\section{personalized accommodation}

\section{Roy McConkey}

Ulster University, Ireland

\section{Brendan Bunting}

Ulster University, Ireland

Fiona Keogh

Genio Ltd., Ireland

\section{Edurne Garcia Iriarte}

Trinity College, Ireland
Journal of Intellectual Disabilities

(C) The Author(s) 2017

Reprints and permission:

sagepub.co.uk/journalsPermissions.nav DOI: $10.1|77 /| 7446295|77| 6546$ journals.sagepub.com/home/jid

@SAGE

\begin{abstract}
A natural experiment contrasted the social relationships of people with intellectual disabilities $(n=110)$ before and after they moved from congregated settings to either personalized accommodation or group homes. Contrasts could also be drawn with individuals who had enduring mental health problems $(n=46)$ and who experienced similar moves. Face-to-face interviews were conducted in each person's residence on two occasions approximately 24 months apart. Multivariate statistical analyses were used to determine significant effects. Greater proportions of people living in personalized settings scored higher on the five chosen indicators of social relationships than did persons living in grouped accommodation. However, multivariate statistical analyses identified that only one in five persons increased their social relationships as a result of changes in their accommodation, particularly persons with an intellectual disability and high support needs. These findings reinforce the extent of social isolation experienced by people with disabilities and mental health problems that changes in their accommodation only partially counter.
\end{abstract}

\title{
Keywords
}

intellectual disability, mental health, social relationships, personalized, support, group homes

\section{Corresponding author:}

Roy McConkey, University of Ulster, Jordanstown, Newtownabbey, BT37 0QB, Ireland.

Email: r.mcconkey@ulster.ac.uk 
Journal of Intellectual Disabilities $X X(X)$

\section{Introduction}

Social exclusion is a common experience for people with disabilities and those with enduring mental health problems (Bogenschutz et al., 2015; Cobigo and Stuart, 2010). The lack of social relationships is a major contributor to the lower quality of life experienced by these individuals (Evans et al., 2007; Merrills et al., 2017). In part this has resulted from the segregated nature of the service supports available to them, notably in terms of living arrangements away from the family home. In many countries, the previous long-stay hospitals or congregated residential settings have been replaced by various community living options; chief of which has been group homes or hostel accommodation (Doyle and Carew, 2016; Killaspy et al., 2016). Although these changes have led to some improvements in the quality of life for people who have been resettled from congregated accommodation, social relationships often remain sparse even after a prolonged period of time (Bigby et al., 2017; Forrester-Jones et al., 2006: McConkey et al., 2007). For example, people have few friends outside of their place of residence, they rarely have visitors and little interactions with neighbours (Chowdhury and Benson, 2011; Robertson et al., 2001).

In Ireland, as elsewhere, the dominant form of supported accommodation has been group homes for persons with intellectual disability; in which up to six or eight persons share an ordinary house or apartment with support staff available on a 24-h basis if required. However, such accommodation can share some of the attributes of congregated settings notably in limiting opportunities for building social relationships (Kozma et al., 2009). More recently the emphasis has shifted towards the provision of more personalized accommodation with people supported to live alone or with a friend in ordinary housing (Mansell and Beadle-Brown, 2009).

Likewise this is a preferred option for people with mental health problems rather than the hosteltype provision commonly provided after hospital discharge. Personalized options provide greater opportunities for realizing people's preferences and aspirations while tailoring support to their needs. To date though, the evidence base for the impact of such accommodation and support arrangements remains limited and especially in terms of promoting social relationships (Harkes et al., 2014).

The opportunity to undertake a natural experiment on this issue arose when Irish services received financial incentives from Genio Trust to support the relocation of people from congregated settings to more personalized arrangements. This Trust was established in 2010 as an Irish registered charity with funding from Atlantic Philanthropies, the Health Services Executive and the Department of Health and Children. Providers of residential services for persons with disability or enduring mental health problems could apply for grants from Genio to facilitate their service users in an individualized way to move either from congregated settings to community group homes or to more personalized arrangements in the community. An independent evaluation was commissioned by Genio of the impact of these moves on people's lives (see McConkey et al, 2013 for full details), with a particular focus on the person's social relationships. Information was gathered before and after people changed their accommodation over a 24-month period. This study took the form of a natural experiment (MRC, 2010) as the selection of participants and the accommodation moves were not controlled by the researchers. However, the study did provide opportunities to contrast changes in participants' social relationships across different accommodation and support options and over time. 
The two main aims of the study were:

- to contrast the social relationships of people with intellectual disability and those with mental health problems living in personalized accommodation and support arrangements with those living in group living settings and

- to monitor changes in the social relationships of people who move from group living arrangements to personalized arrangements.

\section{Method}

\section{Participants}

All 22 service providers - 15 disability agencies and 7 mental health agencies - from across Ireland were grant aided by Genio Trust in 2010 and 2011 to facilitate the relocation of persons from congregated and group living settings to more personalized accommodation and support arrangements. A total of 156 persons were included in the study for whom social relationships data were available before and after moving. Of these, 46 persons had mental health problems, 102 an intellectual disability, and a further 8 persons were considered predominantly physically rather than intellectually disabled. Overall $55 \%$ were male and $65 \%$ were aged 40 years or over. In addition $19 \%$ were in paid employment, all but five were Irish and all but six were single (two were married and four divorced/widowed). People with intellectual disabilities and those with mental health problems were broadly comparable in terms of age, gender and marital status although more people with intellectual disabilities were in paid employment.

All the participants, bar those living with families, had previously resided in group living settings. But at the start of the evaluation, $42(27 \%)$ persons had already moved to personalized arrangements and over the following 24 months, a further 30 (19\%) persons moved from congregated settings to personalized arrangements. During this period also, 42 (27\%) persons moved from congregated settings to community group homes, but $24(15 \%)$ persons still remained in congregated settings as arrangements for moving had not been finalized. In addition, 18 (12\%) persons continued to live with family carers while awaiting a move to their own accommodation.

Each person's support needs were assessed on 13 items related to daily life, such as doing household chores, using public transport, shopping for groceries and filling in forms. These were taken from existing adaptive behaviour scales (e.g. Hatton et al., 2001). A three-point scale was used ranging from 'no support required', 'some support', and 'always needs support'. Across the 13 items, the Cronbach's $\alpha$ were 0.955 at time 1 and 0.881 at time 2 . A count was then made of the number of items for which support was 'always needed', with high scores indicative of needing more support. Participants were then grouped into three levels of support needs depending on scores: low support (28\% of sample); medium support (34\%) and high support (38\%). Only people with intellectual disability fell into the high support grouping.

\section{Accommodation options}

To simplify the presentation of the findings, participants were grouped into two main accommodation options.

Personalized arrangements. Typically these arrangements took the form of rented accommodation in ordinary houses or apartments with people living either alone or with a friend of their choosing. 
Journal of Intellectual Disabilities $X X(X)$

The tenants often chose the property and location as well as decided on furnishings. Most had support staff visiting their home on agreed days and times for a set number of hours per week in accordance with their needs, but a few individuals with higher support needs had staff available to them on a $24 / 7$ basis.

A small group of persons were living with family carers and were being supported to move to their own accommodation and had been allocated a support worker to assist them in planning for the move. They were presently availing of a range of day support and short break services. One person lived with a foster family.

Group living. Initially all the people enrolled in the study were living in a range of congregated settings including campus accommodation of separate bungalows and houses on a shared site as well as hospital wards. In such settings, people had little choice over whom they lived with; they shared communal bathing facilities, dining and sitting rooms and even though some had their own bedroom, others shared sleeping arrangements in ward-like accommodation. Staff were available $24 \mathrm{~h}$ a day although different staff might work across the various housing units and wards.

Some also resided in, or moved to live in group homes, which were ordinary housing in the community shared by up to six persons with support staff available during daytime hours or on a 24-h basis. However, these residents typically had a limited choice of co-residents.

\section{Procedures}

A favourable ethical opinion was obtained from Ulster University Ethics Committee. An easy-toread information sheet describing the study was prepared along with a consent form. All participants were talked through the information sheet and signed informed consent was obtained before the interview commenced. In consenting, it was made clear to participants that they could refuse to answer any questions without giving a reason and they could terminate their participation at any time. They were assured that all their information would be kept private and no one and no service would be identified in any reports. The support they received would be unaffected by their decision to participate or not.

A structured interview schedule was prepared in accord with the wider aims of the evaluation, details of which are available elsewhere (McConkey et al., 2013). Included in the schedule were five items indicative of social relationships, which had been used in previous studies (see later).

A team of eight part-time research associates was recruited and police clearance was obtained for them. They were specially trained to interview persons with intellectual disability. The interviews were usually conducted in a private room in the person's residence. The person interviewed had the option of a member of staff or a relative being present. The interviews generally took around $2 \mathrm{~h}$ with breaks as needed, but they could extend to nearly $4 \mathrm{~h}$. The interviews with 156 individuals took place on two occasions separated by an average of 24 months. For the 312 interviews, $36 \%$ were undertaken with the person alone and the remainder $(64 \%)$ with the person and key worker.

The statistical analysis was conducted using SPSS (version 22) and Mplus (7.11).

\section{Measures and analyses}

Five items indicative of social relationships were included in the wider interview schedule based on past research (e.g. Bigby et al., 2017). They were as follows:(1) have friends over for a meal in the past 12 months; (2) have friends stay over in the past 12 months; (3) get help from a neighbour; 


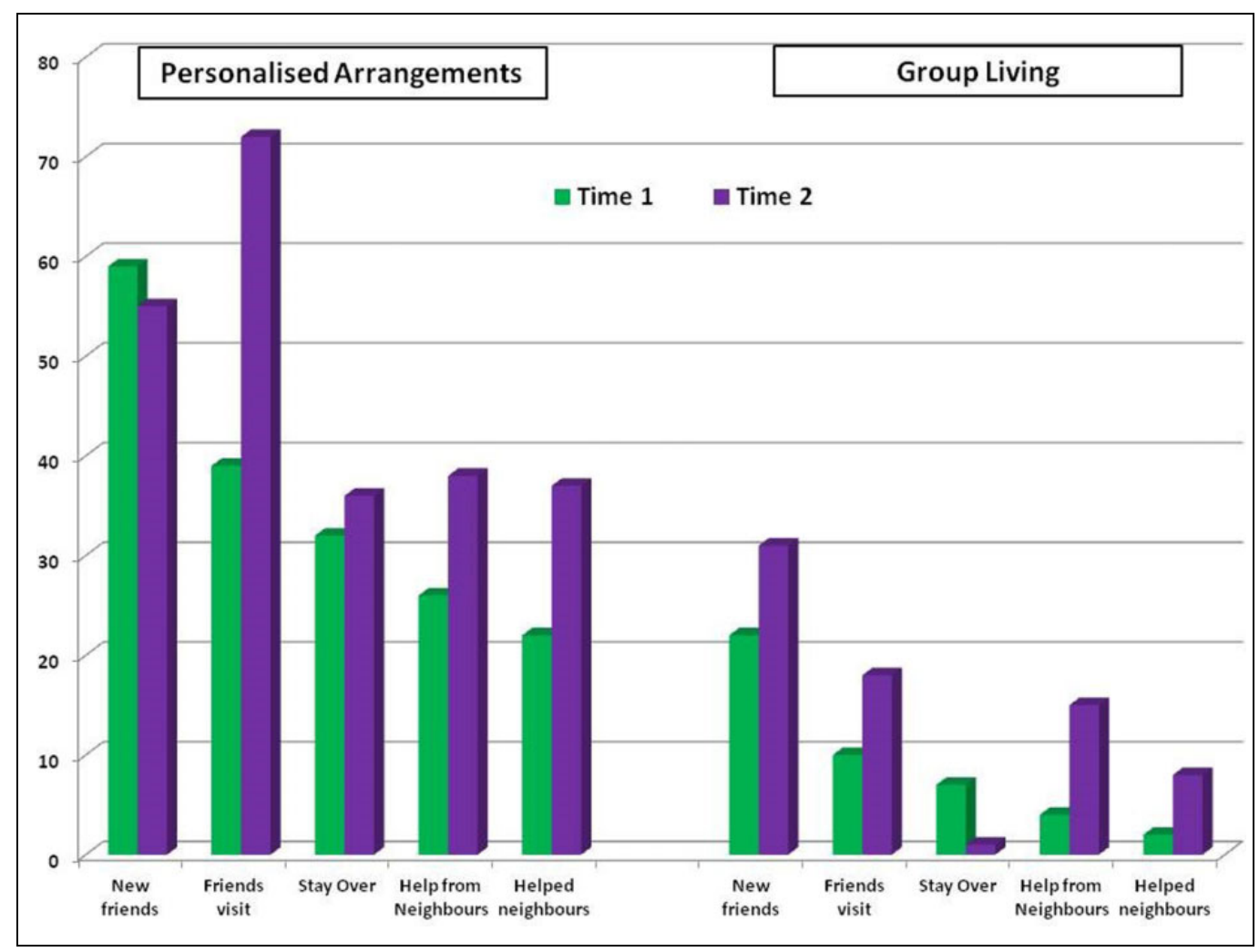

Figure I. The percentage of participants in the two types of accommodation settings who reported the social relationships at time $I$ and time 2. Personalized arrangements: time $I n=6 I$, time $2 n=90$. Group living: time $I n=95$ time $2 n=66$ ).

(4) provide help for a neighbour and (5) made new friends in the past 12 months. Descriptive statistics were initially used to compare those living in personalized arrangements with those who were resident in group settings on the five items and to compare changes over the two time points.

Multivariate statistical analyses were undertaken because of the multiple variables used in the study at two time points. First, responses to the five items were profiled within the context of a latent class analysis. A two-class model was used to describe the data across the two time points as this gave a reasonable description of the data, and the fit indices indicated that there was little to be gained by accepting a third class. The two classes could be typified as having 'social relationships' and 'lack of social relationships'. Multinomial logistic regression based on the two classes were then used to identify the type of change in social relationship that had occurred over the 24-month period and the predictors' association with any change: particularly type of accommodation, level of support needs and condition (mental health or intellectual disability).

\section{Results}

Figure 1 identifies the percentage of persons living in the two types of accommodation, who reported the five indicators of social relationships at the start of the study (Time 1) and after a 
period of 2 years when many more of the study participants had moved from group to personalized accommodation. Because of people moving, the number of people in each type of accommodation varies at time 1 and time 2. On all five indicators, people living in personalized settings reported more social relationships when compared with those living in group settings. The differences were especially apparent at time 1 , but they were maintained at time 2 when more participants had moved to a new form of accommodation (chi-square tests: $p<0.01$ ).

For those living within a personalized setting, the proportion having friends visit for a meal increased significantly over time, with smaller increases in getting and giving help to neighbours (Wilcoxon tests: $p<0.05$ ). A similar pattern of improvement held for persons living in group settings, but here the increases were non significant and the proportions reporting each relationship remained lower compared to persons living in personalized accommodation at time 2 . There were no significant differences on any of the five indicators of social relationships for people with intellectual disability and those with mental health problems at both time points.

\section{Latent class analysis}

A two-class latent variable model over two points in time was used to investigate the changes in these social relationships. The intention behind this analysis was to (a) identify the subgroup of individuals who had fewer social relationships and separate them from those who had more social relationships (b) establish the extent of change within each of these two subgroups over a 2-year period, and (c) determine the factors that might have influenced membership within these subgroups.

The likelihood ratio chi-square test of model fit was 37.92 with 20 degrees of freedom and a $p$ value of 0.01 . The entropy value for classification was 0.74 . This was accepted as an adequate description of the data. Based on this estimated model, at time 1, $30(19 \%)$ persons were in class 1 (more social relationships) and $126(81 \%)$ in class 2 (few social relationships).

\section{Latent transition analysis}

Change and stability in class membership from time 1 to time 2 (when changes in accommodation had taken place) were examined in terms of a latent transition analysis based on latent class membership. The model provided an adequate description of the data (likelihood ratio chi-square $=248.37, \mathrm{df}=999, p$ value $=1.00$ ). The entropy value was 0.68 .

The group that had few social relationships at time $1(n=126: 81 \%)$ dropped to $62 \%$ of the sample $(n=97)$ at time 2 . In all, $19 \%$ of the sample at time $2(n=29)$ had moved from having fewer to more social relationships. By contrast of those who started with more social relationships at time $1(n=30)$ three were classed as having fewer social relationships at time 2 but most maintained their classification as having more social relationships $(=27)$.

\section{Multinomial logistic regression}

A multinomial logistic regression was then used to examine the factors that may have shaped membership in a given class and the transition from one class to another. (This analysis was based on the posterior probabilities obtained from the latent transition analysis and the class membership of participants). The outcome measure was membership in each of the three subgroups: (a) those who were in the class with the least amount of social relationships and who remained in this class on both occasions $(n=97)$; (b) those who moved from class 1 to class 2 and consequently had increased their social relationships $(n=29)$ and (c) those who were classified as having good 
Table I. Multinomial logistic regression for the predictive factors associated with membership within three subpopulations. ${ }^{a}$

\begin{tabular}{|c|c|c|c|c|c|c|}
\hline & & $\begin{array}{l}\text { B (constant } \\
\text { coefficient) }\end{array}$ & $\begin{array}{l}\text { Standard } \\
\text { error }\end{array}$ & $\begin{array}{c}\text { Wald } \\
\text { chi-square }\end{array}$ & Significance & $\begin{array}{l}\text { Exp }(B), \text { odds ratio } \\
\text { (95\% confidence } \\
\text { interval) }\end{array}$ \\
\hline \multirow{8}{*}{$\begin{array}{l}\text { Class I: Fewer } \\
\text { social } \\
\text { interactions } \\
\text { on both } \\
\text { occasions } \\
(n=97)\end{array}$} & Intercept & -2.03 & 0.74 & 7.48 & 0.006 & \\
\hline & Group settings & 3.17 & 0.74 & 18.43 & 0.000 & $23.73(5.59-100.74)$ \\
\hline & $\begin{array}{l}\text { Personalized settings } \\
\text { (reference) }\end{array}$ & 0 & . & . & . & . \\
\hline & Intellectual disability & 2.42 & 0.80 & 9.13 & 0.003 & II.26 (2.34-54.12) \\
\hline & $\begin{array}{r}\text { Mental health } \\
\text { (reference) }\end{array}$ & 0 & . & . & . & . \\
\hline & High support & 3.45 & 0.94 & 13.59 & 0.000 & $31.37(5.02-196.03)$ \\
\hline & Moderate support & 1.53 & 0.74 & 4.23 & 0.040 & $4.59(1.08-19.64)$ \\
\hline & $\begin{array}{l}\text { Low support } \\
\text { (reference) }\end{array}$ & 0 & . & . & . & . \\
\hline \multirow{8}{*}{$\begin{array}{l}\text { Class 2: } \\
\text { Increased } \\
\text { number of } \\
\text { social } \\
\text { interactions } \\
\text { from time } \\
\text { I to time } 2 \\
(n=29)\end{array}$} & Intercept & -1.27 & 0.69 & 3.40 & 0.065 & \\
\hline & Group settings & 0.61 & 0.79 & 0.59 & 0.443 & I.84 (0.39-8.72) \\
\hline & $\begin{array}{l}\text { Personalized settings } \\
\text { (reference) }\end{array}$ & 0 & . & . & . & . \\
\hline & Intellectual disability & 1.83 & 0.78 & 5.54 & 0.019 & $6.24(1.36-28.68)$ \\
\hline & $\begin{array}{r}\text { Mental health } \\
\text { (reference) }\end{array}$ & 0 & . & . & . & . \\
\hline & High support & 2.64 & 0.93 & 8.15 & 0.004 & | 4.02 (2.29-85.90) \\
\hline & Moderate support & 1.33 & 0.74 & 3.24 & 0.072 & $3.78(0.89-16.12)$ \\
\hline & $\begin{array}{l}\text { Low support } \\
\text { (reference) }\end{array}$ & 0 & . & . & . & . \\
\hline
\end{tabular}

${ }^{a}$ The reference group for the subpopulations were those who were classified as having better interactions on both occasions $=27$.

social relationships on both occasions (class 2$)(n=27)$. (The three individuals who had moved from having more to fewer social relationships were excluded from this analysis because of small numbers). The reference group was those who had more social relationships at both time points.

The following predictors were included in the regression model: (a) living in a personalized or group living setting, (b) having an intellectual disability or mental health problem and (c) the level of support required (high, medium, and low).

The result of the regression analysis is shown in Table 1. Individuals living in group settings were more likely to be in the class with fewer social relationships. Also individuals with an intellectual disability, as compared with those with mental health conditions were also more likely to be in this class. Those requiring a high level of support were much more likely to be in the class of having fewer social interactions, and this was also evident among those who required a moderate level of support, at least when compared to those who receive a minimal level of support. In summary, persons who remained in the class with fewer social relationships at time 2 were likely to have stayed within group living settings, to have an intellectual disability and were dependent on high or moderate levels of support. 
Journal of Intellectual Disabilities $X X(X)$

Individuals who changed class from having fewer to more social relationships were more likely to have an intellectual disability rather than a mental health problem. Also those requiring high levels of support were more likely to see their social relationships improve as did those with moderate levels of support. However, the type of accommodation was not a significant factor.

A note of caution: due to the small numbers in the transition condition, the confidence bounds for the significant variables are large but the effect sizes are nonetheless substantial even at the lower confidence levels.

\section{Discussion}

In common with other natural experiments, this study is limited in a number of respects. It was based on a self-selected sample of services and persons who chose to make changes in their living arrangements. They are unlikely to be representative of all persons living in these different accommodation options. Moreover the two broad accommodation types identified in this study could vary greatly in terms of physical accommodation, staffing and location, which could further influence people's opportunities for social relationships. Also the small number of persons within certain subgroupings is a further limitation and additional items relating to social relationships could have been included.

That said, the main value of this natural experiment is twofold: the same persons rated their social relationships at two time points and comparisons can be drawn between those with intellectual disability and enduring mental health problems who were equivalent in terms of their demographics although those with intellectual disability had higher support needs.

Overall nearly two-thirds of participants reported little change in their social relationships as a result of the moves, notwithstanding that other changes were evident in their lifestyle and wellbeing (McConkey et al., 2016, 2017). The data from this study suggests that the lack of social relationships was particularly marked for people with high support needs who continued to reside in group living settings or who had moved from congregated settings to this type of accommodation, such as group homes in the community. However, these findings are based on group averages and some people who had moved to personalized settings and who had less support needs also continued to have fewer social relationships as Figure 1 illustrates.

By contrast, one-third of persons had seen improvements in their social relationships through relocation and particularly those who were living in personalized arrangements. However, over the 2 years of the study, fewer than one in five reported having more social relationships, notably persons with higher support needs. There is the suggestion too that people with intellectual disabilities were more likely to experience improved social relationships when they moved compared to those with mental health problems. Further research is currently being undertaken using qualitative approaches to explore the facilitators and barriers to improving the social relations, especially when people move to personalized settings.

Thus these findings reinforce the extent of social isolation experienced by people with disabilities and mental health problems and how difficult it can be to reduce it. Nonetheless the data give some clues as to what might be done. Personalized living arrangements would seem to offer greater scope for social relationships to be built, as Figure 1 clearly demonstrates, but the support provided to the person to assist them in doing this is probably more crucial rather than the physical setting (Overmars-Marx et al., 2014). For example, in interviews with people in this study who moved to personalized settings and with their support staff, they stressed the need to focus on building social connections within the community and nurturing acquaintances and friendships 
(Garcia-Iriarte et al., 2016). This focussed and intentional approach to building social networks for people who have been institutionalized, needs as much, if not more, attention than the sourcing of accommodation, which is often the primary focus of relocation projects (Howarth et al., 2016).

Although it is no surprise that people with higher support needs are the least likely to have social relationships due to the greater institutionalization they have experienced in Ireland as well as elsewhere compared to their more able peers (Kozma et al., 2009), it is encouraging to note that they too can benefit from relocating to personalized settings. Indeed it may be an essential requirement for this to happen as within group settings the focus of staff support may revolve around residents' basic care needs rather than promoting social interactions (Garcia-Iriarte et al, 2016). Person-centred planning, circles of support and community engagement are more readily arranged for individuals rather than groups even when people are living in small-scale community settings (Craig and Bigby, 2015).

In this study, an attempt was made to find a coherent set of indicators that reflect people's social relationships. Only partial success was achieved in doing this, given the individual variation present in the latent class analyses and the low proportion of variance that was accounted for in the regression analysis. Rather it may be more important to identify individuals' preferences around social contacts and to use these as indicators of change. For example, some people may be reluctant to take the risk of inviting others to their home and likewise they may be wary of having contact with their neighbours. Thus, future studies may need to place more emphasis on an individual's aspirations as to the type of social relationships they value and examine the extent to which these ambitions are realized due to changes in their accommodation and support arrangements. Such an approach would also enable a broader set of indicators of social relationships to be identified that might prove more useful in group-based analyses than those used in this evaluation and other studies.

Finally greater attention should be paid to the environmental influences on the development of social relationships such as the availability of social opportunities locally and the attitudes of neighbours (Overmars-Marx et al., 2014). Likewise the assistance provided by support staff in fostering more social relationships deserves closer scrutiny in all forms of accommodation options (van Alphen et al., 2009).

\section{Authors' Note}

Fiona Keogh is now affiliated to National University of Ireland, Galway.

\section{Acknowledgements}

Thanks to Sharon Brady for her help with data coding.

\section{Declaration of Conflicting Interests}

The author(s) declared no potential conflicts of interest with respect to the research, authorship, and/or publication of this article.

\section{Funding}

The author(s) disclosed receipt of the following financial support for the research, authorship, and/or publication of this article: This evaluation was commissioned and funded by Genio Trust with support from Atlantic Philanthropies, HSE and Department of Health. Our thanks to the project manager Rachel Stevens, 
and to our research assistants: Mairead Brennan, Noelle Fitzgerard, Anna Giblin, Gina McNamara, Siobhan O’Doherty and Maeve O'Halloran.

\section{References}

Bigby C, Bould E and Beadle-Brown J (2017) Comparing costs and outcomes of supported living with group homes in Australia. Journal of Intellectual \& Developmental Disability. Epub ahead of print 1 March 2017. DOI: 10.3109/13668250.2017.1299117.

Bogenschutz AA, Smith C, Carter E, et al. (2015) National research goals for social inclusion of people with IDD. Inclusion 3(4): 211-218.

Chowdhury M and Benson BA (2011) Deinstitutionalization and quality of life of individuals with intellectual disability: a review of the international literature. Journal of Policy and Practice in Intellectual Disabilities 8(4): 256-265.

Cobigo V and Stuart H (2010) Social inclusion and mental health. Current Opinion in Psychiatry 23(5): $453-457$.

Craig D and Bigby C (2015) "She's been involved in everything as far as I can see": supporting the active participation of people with intellectual disability in community groups. Journal of Intellectual and Developmental Disability 40(1): 12-25.

Doyle A and Carew AM (2016) Annual Report of the National Intellectual Disability Database Committee 2015. Dublin: Health Research Board.

Evans S, Banerjee S, Leese M, et al. (2007) The impact of mental illness on quality of life: a comparison of severe mental illness, common mental disorder and healthy population samples. Quality of Life Research 16(1): 17-29.

Forrester-Jones R, Carpenter J, Coolen-Schrijner P, et al. (2006) The Social networks of people with intellectual disability living in the community 12 years after resettlement from long-stay Hospitals. Journal of Applied Research in Intellectual Disabilities 19(4): 285-295.

Garcia Iriarte E, Stockdale J, McConkey R, et al. (2016) The role of support staff as people move from congregated settings to group homes and personalized arrangements in Ireland. Journal of Intellectual Disabilities 20(2): 152-164.

Harkes MA, Brown M and Horsburgh D (2012) Self directed support and people with learning disabilities: a review of the published research evidence. British Journal of Learning Disabilities 42: $87-101$.

Hatton C, Emerson E, Robertson J, et al. (2001) The adaptive behavior scale-residential and community (part I): towards the development of a short form. Research in Developmental Disabilities 22(4): 273-288.

Howarth S, Morris D, Newlin M, et al. (2016) Health and social care interventions which promote social participation for adults with learning disabilities: a review. British Journal of Learning Disabilities 44(1): $3-15$.

Killaspy H, Priebe S, Bremner S, McCrone P, et al. (2016) Quality of life, autonomy, satisfaction, and costs associated with mental health supported accommodation services in England: a national survey. The Lancet Psychiatry 3(12): 1129-1137.

Kozma A, Mansell J and Beadle-Brown J (2009) Outcomes in different residential settings for people with intellectual disability: a systematic review. American Journal on Intellectual and Developmental Disabilities 114(3): 193-222.

McConkey R, Abbott S, Noonan- Walsh P, et al. (2007) Variations in the social inclusion of people with intellectual disabilities in supported living schemes and residential settings. Journal of Intellectual Disability Research 51(3): 207-217.

McConkey R, Bunting B, Ferry F, et al. (2013) An Evaluation of Personalised Supports to Individuals with Disabilities and Mental Health Difficulties. Mullingar, Genio Trust. Available at: http://uir.ulster.ac.uk/ 29587/ (accessed 15 June 2017). 
McConkey R, Keogh F, Bunting B, et al. (2016) Relocating people with intellectual disability to new accommodation and support settings: contrasts between personalised arrangements and group home placements. Journal of Intellectual Disabilities 20(2): 109-120.

McConkey R, Keogh F, Bunting B, et al. (2017) Changes in the self-rated wellbeing of people who move from congregated settings to personalised arrangements and group home placements. Journal of Intellectual Disabilities. Epub ahead of print 24 October 2016. DOI: 10.1177/1744629516674086.

Mansell J and Beadle-Brown J (2009) Dispersed or clustered housing for adults with intellectual disability: a systematic review. Journal of Intellectual \& Developmental Disability 34: 313-323.

Medical Research Council (2010) Using Natural Experiments to Evaluate Population Health Interventions: Guidance for Producers and Users of Evidence. London: MRC

Merrells J, Buchanan A and Waters R (2017) The experience of social inclusion for people with intellectual disability within community recreational programs: a systematic review. Journal of Intellectual \& Developmental Disability. Epub ahead of print 1 February 2017. DOI: 10.3109/13668250.2017.1283684.

Overmars-Marx T, Thomése F, Verdonschot M, et al. (2014) Advancing social inclusion in the neighbourhood for people with an intellectual disability: an exploration of the literature. Disability \& Society 29(2): $255-274$.

Robertson J, Emerson E, Gregory N, et al. (2001) Social networks of people with mental retardation in residential settings. Mental Retardation 39(3): 201-214.

Van Alphen LM, Dijker AJH, Van Den Borne HW, et al. (2009) The significance of neighbours: views and experiences of people with intellectual disability on neighbouring. Journal of Intellectual Disability Research 53: 745-757. 